\title{
Designing an irrigation system using photovoltaic energy by considering crop type in Fergana Valley
}

\author{
Şakir Kuzey ${ }^{1 *}$, Cihat Şeker $^{2}$, Mohamed Elweddad $^{2}$, M. Tahir Güneşer ${ }^{2}$ \\ ${ }^{1}$ Giresun University, Sebinkarahisar Vocational Schools of Tech. Sciences, Electricity and Energy \\ Department, 28400 Giresun, Türkiye \\ ${ }^{2}$ Karabuk University, Engineering Faculty, Electrical and Electronics Engineering Department, 78100 \\ Karabuk, Türkiye
}

\begin{abstract}
Today, the importance of energy cost and efficiency is gradually increase. The decrease in drinking water and agricultural water resources, increases the interest in drip irrigation systems in agricultural irrigation. Environmentally friendly photovoltaic drip irrigation systems (PVDIS) are the appropriate solution in regions where there is no electricity distribution network, where it is far away, or where power cuts are frequently. This study is carried out in the Fergana Valley of Uzbekistan. Regional climate data obtained from Climwat 2.0 software are processed in Cropwat 8.0 software. Crops that are both the source of livelihood of the people of the region and that can be used in this study have been determined. Annual and daily water needs are analyzed so that these crops are irrigated every seven days. A system is designed by taking the data of the crop with the highest water requirement as a reference. The drip irrigation system is set up in a PVsyst 7.1.7 simulation environment to pump $114.24 \mathrm{~m}^{3}$ of water daily from a 5 -meter-deep river with a $1.8 \mathrm{~kW}$ photovoltaic system. The efficiency of the system is $58.7 \%$ and the efficiency of the pump is $34.5 \%$. Crop water need is met at the rate of $98.87 \%$. It is predicted that the designed and analyzed PVDIS will provide efficiency in energy and water resources.
\end{abstract}

\section{Introduction}

Water is the basic food source for all living things on earth. Two-thirds of our world and our bodies are made up of water. This highlights the importance of water for life. Irrigation is the delivery of the water to the plant roots at the right time and amount. Thus, the water that plants need to go on growing, and which cannot be met naturally is provided [1-3].

From past to present, many methods have been developed to pump water with minimum power consumption. Quite different power sources such as human and animal power, wind energy, solar energy, and fossil fuels have been utilized [4-6].

Some regions of Uzbekistan are in the arid and semi-arid climate zone. Plants grown in these regions do not receive sufficient precipitation. It should be irrigated with the most appropriate method to maximize yield and quality. Also, the population has been increasing rapidly in recent years. In response to the increasing population, enough energy cannot be obtained from existing energy sources. All countries of the world are turning to new strategies to meet their energy needs. This makes it necessary to investigate the use of renewable energy sources [7-9]. 
Solar energy is one of the most important renewable energy sources. The use of solar energy in agricultural irrigation reduces the total production costs. Irrigation cost has the largest share in production costs. Solar irrigation systems require no daily maintenance and can be easily installed anywhere rich in sunlight. Besides, solar irrigation systems have less negative impact on the environment compared to non-renewable energy sources. Therefore, they are more preferred than non-renewable energy sources [10].

Considering some values related to solar radiation intensity, the variation of the amount of power obtained from the PV water pumping system is investigated [11]. The size, life cycle, and cost of a system that can pump an average of $60 \mathrm{~m}^{3}$ of water per day in Algeria have been analyzed. It has been evaluated economically [12]. PV installation was used to pump water to the orchards. The design criteria of the system using the drip irrigation technique were determined [13]. The efficiency of the water pumping system directly connected to the DC power generating PV unit is evaluated. An experimental study has been done [14]. In Tunisia, 3000 hours of sunshine duration per year and $6 \mathrm{kWh} / \mathrm{m}^{2}$ day of solar energy are used for pumping water [15]. An optimization study has been carried out for sizing an AC motor PV irrigation system [16]. Electricity is produced from solar energy based on the PV principle. A centrifugal pump is operated with the generated electricity. With this pump, a solar irrigation system has been developed [17].

In this study, a PVDIS is designed from the river or the lake to the tank. PVDIS design and analysis is made for the Fergana city, located in the Fergana Valley of Uzbekistan. The region, where many crops are grown, has very fertile soils. Agricultural products such as cotton, wheat, and corn, which contribute to the economy of Uzbekistan, are grown in this region. In addition, the local people in this region earn their living from agriculture. For this reason, Fergana Valley is chosen as the pilot region in this study. In the study, a solar energy system with a power of $1.80 \mathrm{kWh}$ is installed. The system has a daily pumping capacity of $114.24 \mathrm{~m}^{3}$ from the water source, whose depth is estimated to be 5 meters. The design of this system has been done in a simulation environment.

\section{Material and Method}

\subsection{Land Parameters}

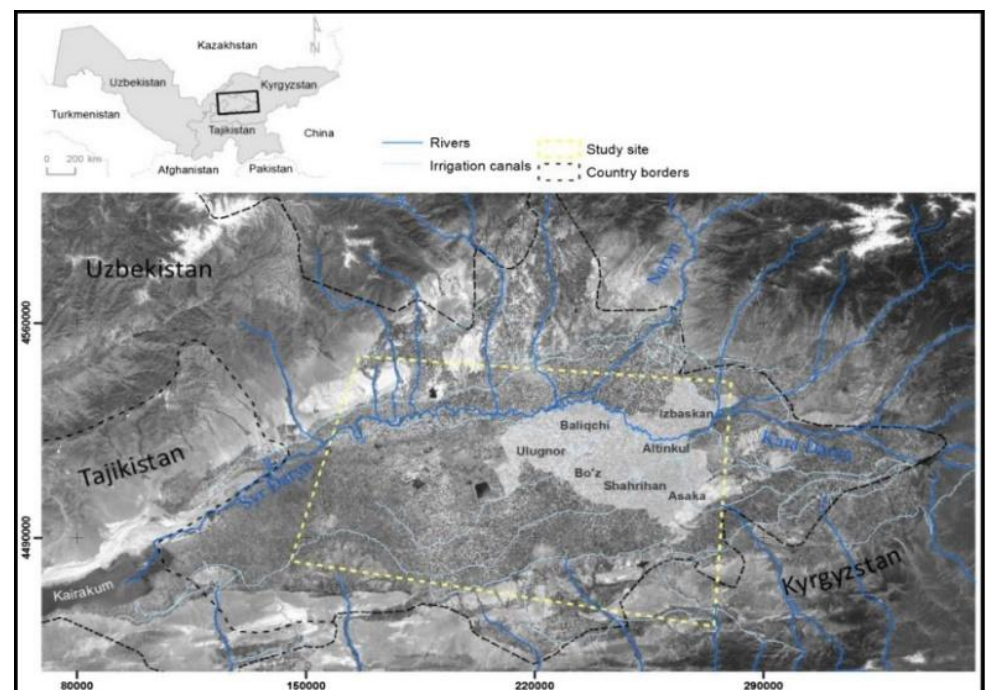

Fig. 1. Location map of the research area 


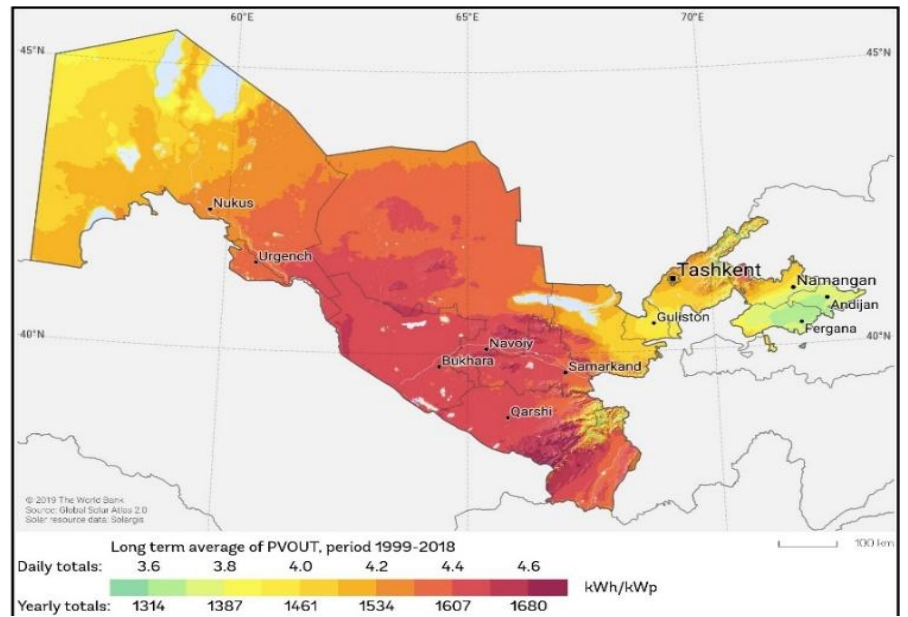

Fig. 2. Photovoltaic power potential Uzbekistan

\section{Temperature - Humidity}

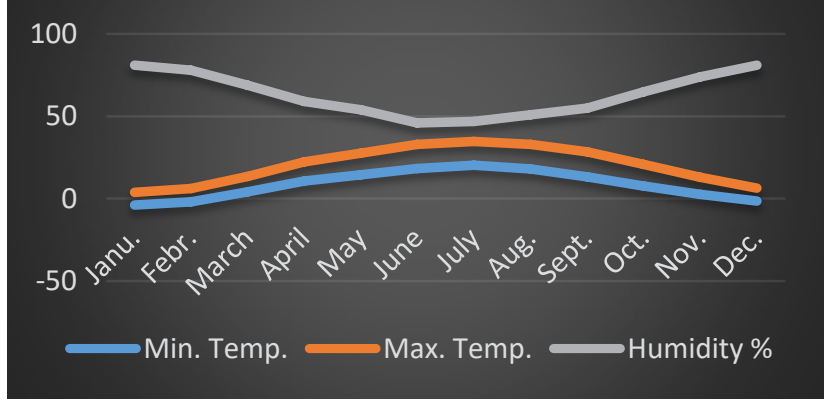

(a)

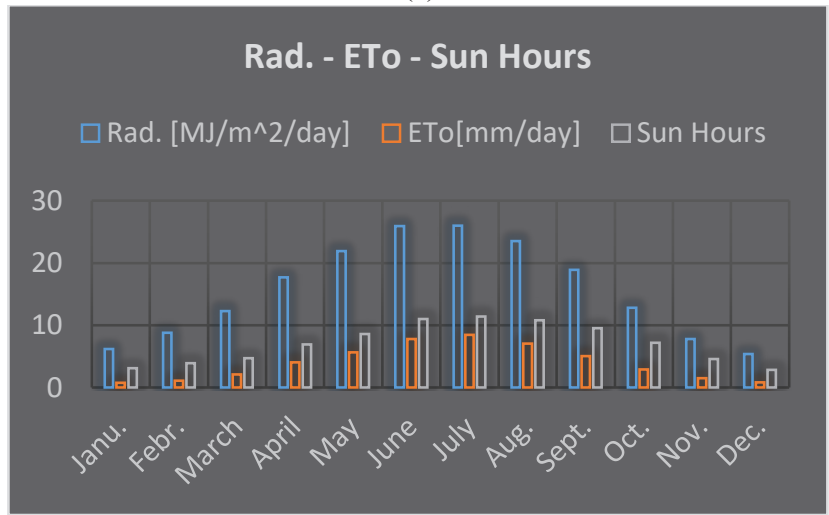

(b)

Fig. 3. Fergana valley (a) Temperature and Humidity (b) Radiation, ETo ve Sun hours

Solar energy is an important factor in reducing farmer costs and increasing crop yields. With the designed photovoltaic irrigation system, the cost of crop irrigation is significantly reduced. In this study, the design and analysis of a river-to-tank photovoltaic drip irrigation system for the Fergana Valley of Uzbekistan are carried out. Fergana valley is in the southeast of Uzbekistan. It is located between two mountains, Tien Shan in the north and 
Alai in the south [18]. In Fig. 1 [19], the study area and the irrigation resources of the region are shown. The region is rich in terms of rivers and irrigation channels. For this reason, it has an infrastructure compatible with PVDIS.

The climate of the region is continental. The average annual precipitation is between 100and 200-mm. Potential evapotranspiration occurs up to $1300 \mathrm{~mm}$ [20]. Fig. 2 shows the photovoltaic power potential of Uzbekistan. In the figure, the photovoltaic power potential of the regions increases as one move towards the dark red color. Fergana Valley is below the country average in terms of photovoltaic power potential. However, this region is preferred for the study because of the high agricultural crop potential of the region. Majority of the people earn their living from agriculture. The irrigation canals in the region and the river structure are suitable for agricultural irrigation. It is predicted that the efficiency of PVDIS will be higher in regions with the high photovoltaic power potential of Uzbekistan.

Fig. 3 shows the climatic data of the Fergana valley. In June, humidity is the lowest level with an average value of $46 \%$. In January and December, the humidity the highest level with an average value of $81 \%$. The average temperature in the valley is the lowest in January with $3.9^{\circ} \mathrm{C}$. It is the highest level with $34.7^{\circ} \mathrm{C}$ in July. While the sunshine duration is the highest with 11.4 hours in July, it has the lowest value with 2.8 hours in January.

\subsection{Irrigation System Components and Simulation Environment}

The climate data of the region determined in this study are obtained from the CLIMWAT 2.0 software. Climwatt 2.0 software has climate data stations at certain points around the world. The data obtained from the station of this software located in the Fergana region at the coordinates Latitude: $40.36^{\circ} \mathrm{N}$, Longitude: $71.75^{\circ} \mathrm{E}$ are defined to the CROPWAT 8.0 software. Thus, the water needs of cotton, winter wheat, and corn produced in the region are determined. The most suitable software to determine the irrigation water requirement of any plant in any region is CROPWAT 8.0 [21].

The CROPWAT model is an irrigation management model. It determines the water requirements and irrigation needs of the crop. In this model, the potential evaporation (ETo) parameter is used. Potential evaporation (ETo) is estimated using crop parameters and the Penman-Monteith equation.

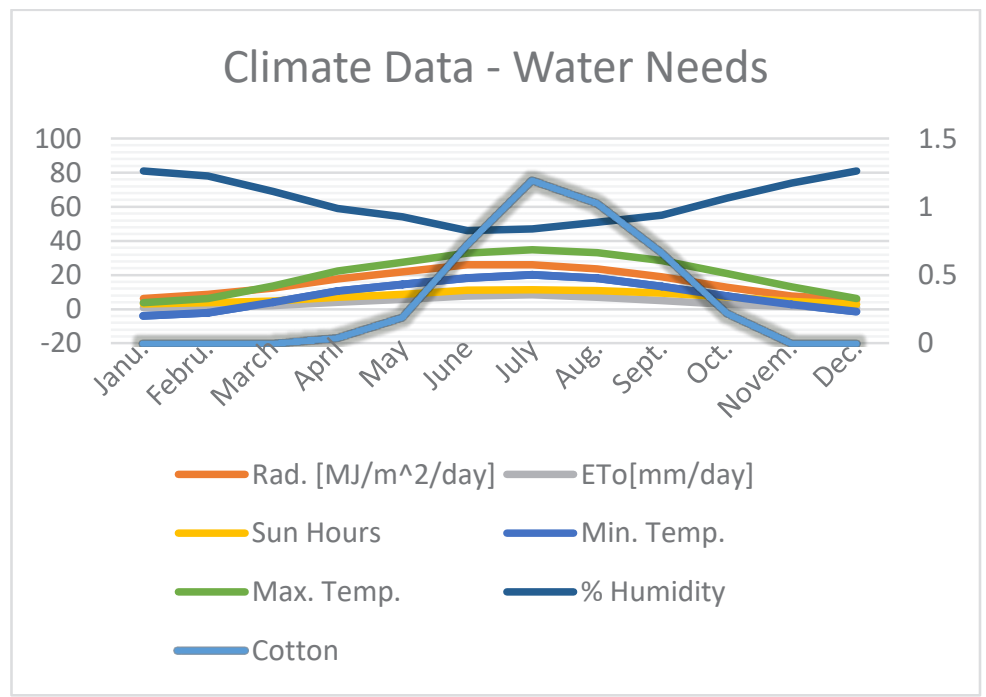

Fig. 4. The relationship between climate data and cotton water need 
Table 1. System data

\begin{tabular}{|c|c|c|c|}
\hline Parameter & Characteristic & Parameter & Characteristic \\
\hline Design location & $\begin{array}{c}\text { Uzbekistan-Fergana } \\
\text { Latitude: } 40.38^{\circ} \\
\text { Longitude: } 71.78^{\circ}\end{array}$ & Pipe & DN100 \\
\hline Altitude & 585 meter & Water needs & $114.24 \mathrm{~m}^{3} /$ day \\
\hline System type & Lake or river to storage & Pump & Generic PS1200 SJ12-3 \\
\hline Tilt & $33^{\circ}$ & Power conditioning unit & MPPT-DC Converter \\
\hline Azimuth & $-3^{\circ}$ & PV module & Generic Aleo S-59/300 \\
\hline Meteo data & Meteonorm 7.3 & PV module in series & 2 \\
\hline Pump level & -7 meter & PV nodule in parallel & 3 \\
\hline Lake level & -5 meter & Module area & $10 \mathrm{~m}^{2}$ \\
\hline Storage tank & $600 \mathrm{~m}^{3}$ & Total modules power & $1,80 \mathrm{kWp}$ \\
\hline Number of elbows & 4 & Total PV P PPP & $1.635 \mathrm{kWp}$ \\
\hline Other friction losses & $5 \%$ & Water pumping (year) & $41226 \mathrm{~m}^{3}$ \\
\hline
\end{tabular}

The solar power system is designed in the Pvsyst 7.1.7 simulation environment. The data of the cotton is used when determining the amount of water to be pumped into the land. Because the crop with the highest water requirement is cotton. The values of the month when cotton needs the most water determined the system capacity. The water requirement of cotton is given in Fig. 4. It is clearly seen that cotton needs the most water in July. In this month, the water requirement of cotton reaches 1.19 liters/second/ha. The parameters used in the Pvsyst 7.1.7 simulation environment are summarized in Table 1.

\section{Results and Discussion}

System efficiency and pump efficiency were calculated $58.7 \%$ and $34.5 \%$ respectively. The values found are low in terms of performance. Although these values seem low in terms of performance, in fact, while the tank capacity was calculated as $571.2 \mathrm{~m}^{3}$, it was ignored due to the force of the actual conditions, such as it designed as $600 \mathrm{~m}^{3}$.

The design of the irrigation system is done in the PVsyst 7.1.7 simulation environment. There is no pump with optimum values for every system designed in a simulation environment. In this case, the optimum pump possible in the simulation environment is selected. Generic brand PS1200 SJ12-3 water pump with $1.2 \mathrm{~kW}$ power is selected.
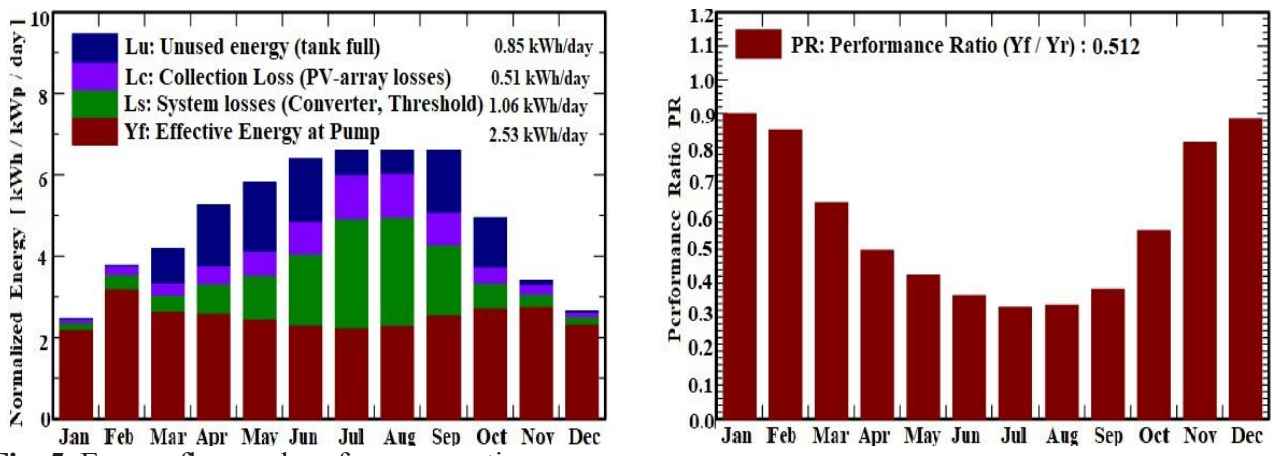

Fig. 5. Energy flow and performance ratio

\section{Conclusions}

In the design, a maximum PV power of $1.80 \mathrm{~kW}$ and a $1.2 \mathrm{~kW}$ pumped $41226 \mathrm{~m}^{3}$ of water annually to the tank. In the months when the amount of sunshine duration and radiation increased, energy production exceeded the desired level. Unused energy is wasted. This has 
reduced the efficiency and performance ratio. Therefore, in real practice, the photovoltaic system design should be done with the optimum value pump. In the months when the sunshine duration and the amount of radiation decreased, the energy produced approximately met the water need. For this reason, the efficiency and performance ratio of the system has increased. Since the most important purpose here is to meet the water need, the decrease in yield is negligible. The system met the water needs of the crops at a rate of $98.87 \%$. Choosing a large tank prevents energy loss. In addition, if the photovoltaic drip irrigation system is connected to the electricity distribution network, energy can be transferred from the system to the grid. Thus, efficiency can be increased.

\section{References}

1. A. Hafian, M.N. Kabbaj, A. Abouabdillah, M. Benbrahim, A. Bouazi, A New Approach for Optimal Sizing of Photovoltaic Pumping Systems for Irrigation, 2020 5th International Conference on Renewable Energies for Developing Countries (REDEC) (2020)

2. Z. Glasnovic, J. Margeta, A model for optimal sizing of photovoltaic irrigation water pumping systems, Sol. Energy 81, 904-916 (2007)

3. A. Turaev, K. Muratov, O. Tursunov, Comprehensive analysis of the change of pop solar power station output parameters in relation to ambient temperature, IOP Conf. Ser.: Earth Environ. Sci. 614, 012003 (2020)

4. J. Reca-Cardeña, R. López-Luque, Design Principles of Photovoltaic Irrigation Systems, in Advances in Renewable Energies and Power Technologies, Elsevier, Netherlands (2018)

5. K. Assalaou, L. Bouhouch, L. Elmahni, Development and Optimization of a Photovoltaic Pumping Irrigation System, Int. J. Adv. Res. 5, 513-521 (2017)

6. R.J. Chilundo, P.C.M. Carvalho, M.M.N. Diniz, A.M.E. Bezerra, Photovoltaic powered irrigation system applied to familiar agriculture, Renew. Energy Power Qual. J. 95-100 (2015)

7. V. Nath Maurya, G. Ogubazghi, B. Prasad Misra, A. Kumar Maurya, D. Kaur Arora, Scope and Review of Photovoltaic Solar Water Pumping System as a Sustainable Solution Enhancing Water Use Efficiency in Irrigation, Am. J. Biol. Environ. Stat. 1, 18 (2015)

8. S.S. Chandel, M. Nagaraju Naik, R. Chandel, Review of solar photovoltaic water pumping system technology for irrigation and community drinking water supplies, Renewable and Sustainable Energy Reviews 49, 1084-1099 (2015)

9. M.B. Hayat, D. Ali, K.C. Monyake, L. Alagha, N. Ahmed, Solar energy-A look into power generation, challenges, and a solar-powered future, Int. J. Energy Res. 43, 10491067 (2019)

10. S. Hilarydoss, Suitability, sizing, economics, environmental impacts and limitations of solar photovoltaic water pumping system for groundwater irrigation-a brief review, Environ. Sci. Pollut. Res. (2021)

11. B. Yesilata, Z.A. Firatoglu, Effect of solar radiation correlations on system sizing: PV pumping case, Renew. Energy 33, 155-161 (2008)

12. B. Bouzidi, P.E. Campana, Optimization of photovoltaic water pumping systems for date palm irrigation in the Saharan regions of Algeria: increasing economic viability with multiple-crop irrigation, Energy, Ecol. Environ. 6(9), 1-28 (2020)

13. B. Bravdo, E.L. Proebsting, Use of Drip Irrigation in Orchards, Horttechnology 3, 44 49 (1993) 
14. P. Upadhyay, R. Kumar, A ZVS-ZCS quadratic boost converter to utilize the energy of PV irrigation system for electric vehicle charging application, Sol. Energy 206, 106-119 (2020)

15. B.G. Belgacem, Performance of submersible PV water pumping systems in Tunisia, Energy Sustain. Dev. 16, 415-420 (2012)

16. M. EL-Shimy, Sizing optimisation of stand-alone photovoltaic generators for irrigation water pumping systems, Int. J. Sustain. Energy 32, 333-350 (2013)

17. V. Sontake, A. Tiwari, V. Kalamkar, Performance investigations of solar photovoltaic water pumping system using centrifugal deep well pump, Therm. Sci. 24, 2915-2927 (2020)

18. R. Filcak, Migration and the environment in Central Asia: the case of Fergana Valley, Overview Study (2008)

19. F. Löw, C. Biradar, E. Fliemann, J.P.A. Lamers, C. Conrad, Assessing gaps in irrigated agricultural produvtivity through satellite earth observations-A case study of the Fergana Valley, Central Asia, International Journal of Applied Earth Observation and Geoinformation 59, 118-134 (2017)

20. Kh. Umurov, Sh. Kenjabaev, G. Stulina, V. Dukhovny, Development of methods for irrigation monitoring in Central Asia - on example of Fergana Valley, Scientific reportfor the CAWa project, Tashkent (2010)

21. C. Karaca, D. Büyüktaş, B. Tekelioğlu, Kıyas Bitki Su Tüketiminin (ETo ${ }_{\mathrm{o}}$ ) Hesaplanması Amacıyla Kullanılan Bilgisayar Yazılımlarının Karşılaştırılması, Gaziosmanpasa Journal of Scientific Research 6, 118-128 (2017) 